\title{
Tuberculosis peritoneal, un diagnóstico diferencial para ascitis en cirrosis
}

\section{Peritoneal tuberculosis, a differential diagnosis for ascites in cirrhosis}

\author{
Sandra B. Amado-Garzón, ${ }^{*}$ (ㄱ) Carlos Andrés Mejía-Gómez. ${ }^{2}$ (16)
}

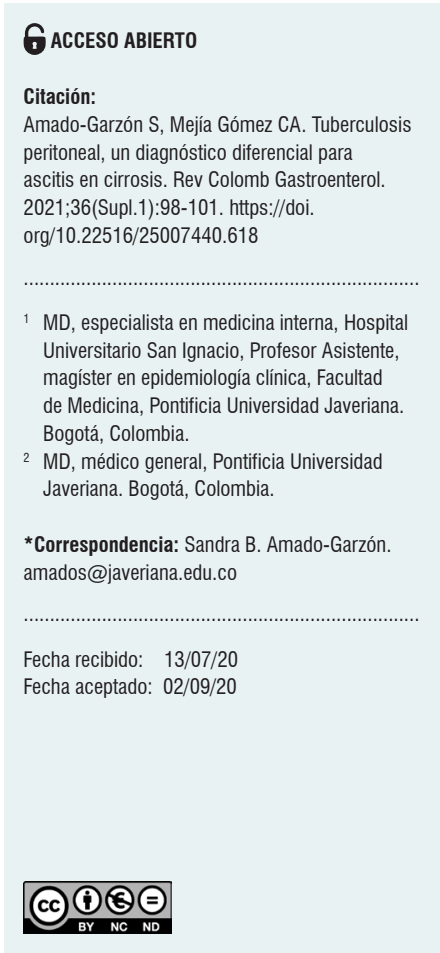

\begin{abstract}
Resumen
Se presenta el caso de un paciente con antecedente de consumo crónico de alcohol, que consultó por dolor abdominal inespecífico, fiebre intermitente no cuantificada y pérdida de peso, con posterior aumento del perímetro abdominal. Se encontró ascitis y hallazgos en imágenes que sugerían cirrosis. El estudio del líquido ascítico fue no hipertensivo con predominio de linfocitos y niveles de adenosina-desaminasa (ADA) elevados. La ecografía y tomografía de abdomen mostraron el engrosamiento del peritoneo y la biopsia peritoneal por laparoscopia fue compatible con enfermedad granulomatosa, con reacción en cadena de la polimerasa (PCR) positiva para Mycobacterium tuberculosis en un paciente sin otras causas de inmunosupresión. Este caso muestra la necesidad de mantener una alta sospecha clínica de TB en patologías abdominales con clínica inespecífica, aun en pacientes sin inmunocompromiso claro.
\end{abstract}

\section{Palabras clave}

Ascitis, cirrosis hepática, peritoneo, tuberculosis gastrointestinal.

\section{Abstract}

This is the case of a patient with a history of chronic alcohol consumption, who consulted for nonspecific abdominal pain, intermittent fever, and weight loss, with subsequent increase in the abdominal perimeter. Ascites and imaging findings suggestive of cirrhosis were found. The study of ascitic fluid was non-hypertensive with a predominance of lymphocytes and elevated adenosine deaminase (ADA) levels. Ultrasound and abdominal tomography showed peritoneal thickening. Laparoscopic peritoneal biopsy was compatible with granulomatous disease, with positive PCR for Mycobacterium tuberculosis in a patient with no other causes of immunosuppression. This report shows the importance of keeping a high index of suspicion for TB in patients with abdominal pathology, even in those without evident inmunocompromise.

\section{Keywords}

Ascites; Hepatic cirrhosis; Peritoneum; Gastrointestinal tuberculosis.

\section{INTRODUCCIÓN}

La tuberculosis (TB) peritoneal constituye el $1 \%-2 \%$ de los casos de TB general, $31 \%-58 \%$ de los casos de TB gastrointestinal y se describe asociación con TB pulmonar en 3,5\% de los casos (1). Sigue siendo un reto diagnóstico debido a lo inespecífico de los hallazgos clínicos y su naturaleza paucibacilar, con riesgos importantes como sepsis, obstrucción intestinal e infertilidad en las mujeres, por lo que se considera un diagnóstico casi obligatorio a descartar en el diagnóstico de ascitis no hipertensiva (2).

Para 2018 se estimaron 10 millones de nuevos casos de TB en el mundo, de los cuales 8,6 \% tenía virus de la inmunodeficiencia humana (VIH) (3). En Colombia, se reportaron al Sistema de Vigilancia en Salud Pública (SIVIGILA) 14480 casos, de los cuales el 11,1 \% tenía coinfección con VIH (4). Aunque en los últimos años ha sido claro el aumento de casos de TB asociados con la enfermedad por 
VIH/sida, de 1,45 millones de muertes registradas por la Organización Mundial de la Salud (OMS), solo 251000 eran positivas para VIH, lo que refleja la importancia de seguir contemplando esta entidad en poblaciones sin compromiso inmunológico grave o evidente (3).

\section{CASO CLÍNICO}

Se trata de un hombre de 47 años, natural de la zona rural de Boyacá, procedente de Bogotá, conductor y consumidor de cerveza una vez por semana, por cerca de 15 años, sin otros antecedentes, quien consultó por 20 días de aumento del perímetro abdominal, dolor difuso tipo peso y de 4 meses, sensación de alza térmica no cuantificada ocasional y pérdida de $15 \mathrm{~kg}$ de peso. Había consultado a otras instituciones donde le dieron manejo sintomático con antiácidos. Al examen clínico de ingreso presentaba signos vitales normales, índice de masa corporal (IMC) de 22, distensión abdominal con signos de ascitis moderada y leve dolor a la palpación difusa sin signos de irritación peritoneal. Los paraclínicos de ingreso mostraron hemograma con anemia normocítica leve (hemoglobina de $11,4 \mathrm{~g} / \mathrm{dL}$ ), recuento leucocitario y de plaquetas normales; proteína $\mathrm{C}$ reactiva y velocidad de sedimentación globular (VSG) elevadas. También se encontró hiponatremia de 129, con función renal, parcial de orina y radiografía de tórax normales.

En la ecografía abdominal se documentó ascitis, hígado de contornos lobulados y de menor tamaño, con Doppler esplenoportal y endoscopia de vías digestivas altas (EVDA) que mostraron cambios sugestivos de hipertensión portal; várices esofágicas y esplénicas con esplenomegalia leve. Las transaminasas, fosfatasa alcalina y bilirrubinas fueron normales; los tiempos de coagulación se encontraron prolongados, con tiempo de protrombina (TP) de 15,8 segundos, índice internacional normalizado (INR) de 1,44, tiempo de tromboplastina parcial (TTP) de 41,8 y alfafetoproteína normal. Como estudios complementarios se realizaron serologías para hepatitis $\mathrm{B}$ y $\mathrm{C}$ que fueron negativas, anticuerpos mitocondriales y antimúsculo liso igualmente negativos.

El citoquímico del líquido ascítico mostró un gradiente de albúmina suero-líquido (GASA) de 0,6 compatible con ascitis no hipertensiva; leucocitos de $2400 / \mathrm{mm}^{3}, 100 \%$ linfocitos, con glucosa en $82,4 \mathrm{mg} / \mathrm{dL}$ y coloración de Gram negativa para gérmenes. Se amplió el estudio con niveles de adenosina-desaminasa (ADA) en el líquido peritoneal con un valor de $102 \mathrm{U} / \mathrm{L}$ (referencia < $36 \mathrm{U} / \mathrm{L}$ ) y el citológico mostró linfocitosis y fue negativo para malignidad. Se realizó una tomografía axial computarizada (TAC) de tórax y abdomen con el fin de descartar una neoplasia como diagnóstico diferencial. La TAC de abdomen mostró cambios en la densidad del peritoneo con engrosamiento, múltiples nódulos pequeños en el tercio superior del abdomen que realzaban con el medio de contraste (Figura 1), hígado pequeño y ascitis abundante; y la TAC de tórax mostró escaso derrame pleural bilateral. Se definió realizar una laparoscopia para la toma de biopsias en la que se evidenció un compromiso extenso de todo el peritoneo por micronódulos amarillentos, algunas adherencias interasas, abundante líquido verdoso no purulento en la cavidad, así como hígado de aspecto cirrótico con algunos micronódulos; se tomó biopsia de peritoneo e hígado. El estudio histológico del peritoneo fue compatible con inflamación granulomatosa, con tinción de Ziehl-Neelsen (ZN) negativa (Figura 2), pero con reacción en cadena de la polimerasa (PCR) positiva para Mycobacterium tuberculosis. El enzimoinmunoanálisis de adsorción (ELISA) para VIH fue negativo.

Se realizó el tratamiento con un esquema supervisado para TB por 9 meses con una adecuada evolución clínica y paraclínica en el seguimiento ambulatorio, normalización del peso corporal y resolución de la ascitis sin deterioro de la función hepática al terminar la primera fase de tratamiento. Igualmente, se continuó el manejo y seguimiento por hepatología para el cuadro de cirrosis Child-Pugh B de etiología alcohólica asociada.

\section{DISCUSIÓN}

Es bien conocido que la TB abdominal tiene una variada presentación clínica $y$, por tanto, puede mimetizar otras enfermedades abdominales frecuentes y no frecuentes. Fue descrita por primera vez en 1843 y puede ser causada por cualquiera de los miembros del complejo de Mycobacterium (M. tuberculosis, M. africanum, M. bovis, M. caprae, $M$. microti, entre otros) conocidos como bacilos ácido-alcohol resistentes y se caracteriza por su naturaleza paucibacilar $(1,2)$. Es la sexta causa más frecuente de TB extrapulmonar, y la variedad peritoneal es la responsable de hasta el $50 \%$ de dichos casos (5). Algunas asociaciones o posibles factores de riesgo identificados para el desarrollo de TB peritoneal son la infección por VIH, la diálisis peritoneal, la diabetes tipo 2, el uso de fármacos inmunosupresores como corticosteroides y antifactor de necrosis tumoral alfa (anti-TNF- $\alpha$ ), y la cirrosis alcohólica, como se ilustra en el caso que presentamos (5).

El mecanismo de infección del peritoneo por el bacilo puede ser por: vía hematógena o linfática desde un foco pulmonar, ingestión de material infectado pasando a ganglios linfáticos mesentéricos y retroperitoneales que pueden romperse y diseminar la micobacteria, extensión directa desde los órganos vecinos o contaminación directa del peritoneo en pacientes con enfermedad renal crónica (ERC) en diálisis peritoneal $(1,6)$. En una evaluación posterior, este paciente refirió ingesta de leche no pasteurizada 


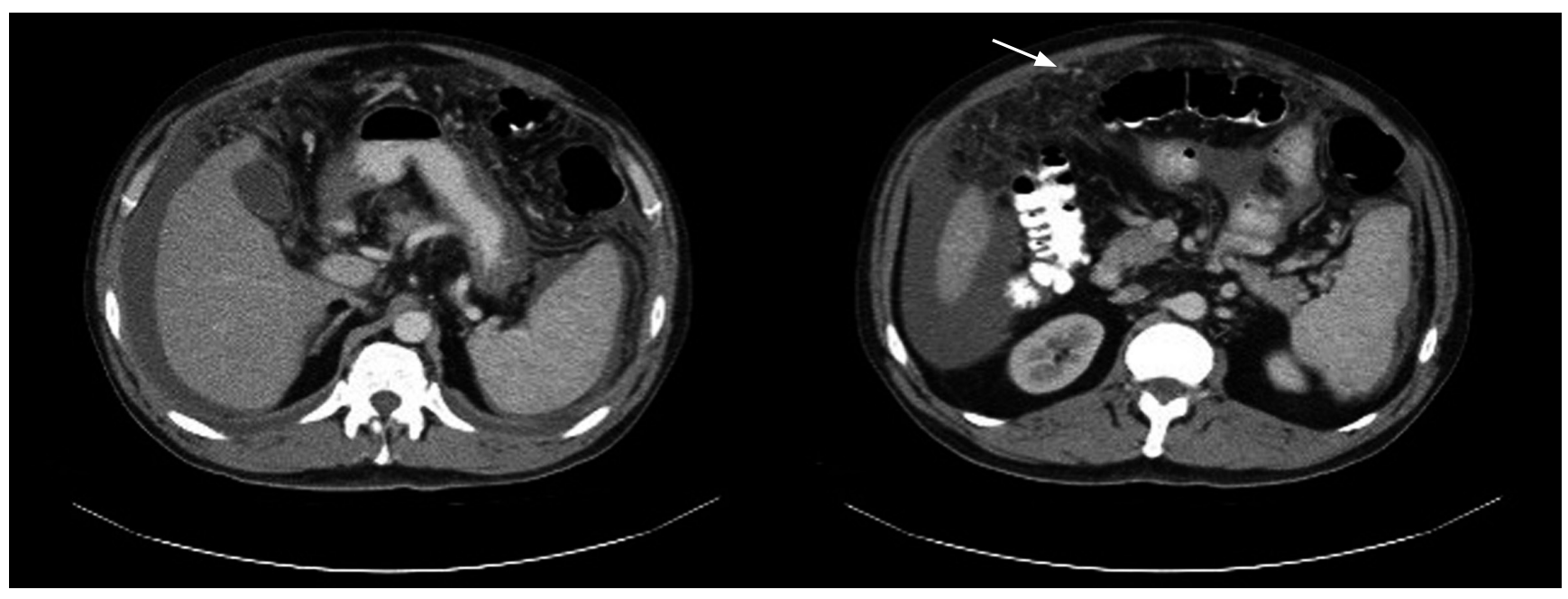

Figura 1. TAC de abdomen contrastada. Hígado pequeño, engrosamiento y múltiples nódulos pequeños en el peritoneo que realzan con el medio de contraste.
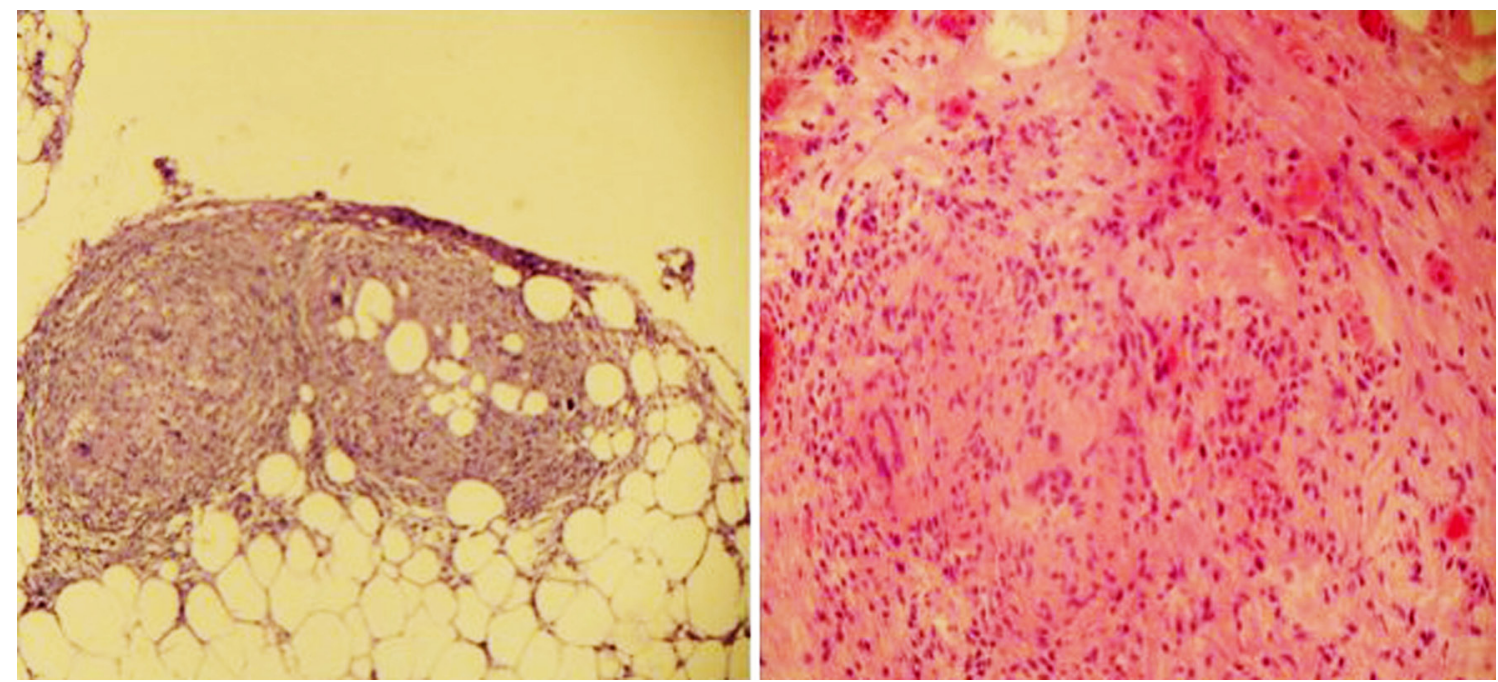

Figura 2. Estudio histopatológico. Coloración de hematoxilina-eosina con evidencia de inflamación crónica granulomatosa sugestiva de TB. Coloración ZN negativa para bacilo resistente a ácido-alcohol.

que podría sugerirse como posible mecanismo fisiopatológico. Entre los hallazgos clínicos se describe la presencia de ascitis, dolor abdominal, fiebre, pérdida de peso, hiporexia y distensión abdominal. Dado lo inespecífico del cuadro junto con el carácter subagudo de la enfermedad, suele haber tardanza en el diagnóstico hasta en un $70 \%$ de los casos, por lo que se debe mantener un bajo umbral de sospecha (5).

En caso de ascitis, es fundamental observar sus características como el color amarillo cetrino o incluso hemático (1); la concentración de proteínas usualmente es $>30 \mathrm{~g} / \mathrm{L}$ y la celularidad usualmente es $>400 \mathrm{cel} / \mathrm{mL}$, de predomi- nio linfocítico, que constituye un exudado con GASA $<1,1$ $\mathrm{g} / \mathrm{dL}$. No obstante, en casos de TB peritoneal con cirrosis concomitante, como el caso que presentamos, este índice pierde sensibilidad con valores que varían entre el $29 \%$ y el $88 \%$; estos pacientes, al igual que aquellos en diálisis peritoneal, pueden presentar celularidad con predominio neutrofílico, por lo que se debe tener presente la posible confusión con peritonitis bacteriana espontánea $(1,5)$.

El estudio citológico del líquido es necesario ante el diagnóstico diferencial de neoplasia. La medición de lactato-deshidrogenasa (LDH) en el suero o líquido es menos sensible y específica, y no se usa de rutina. Aunque el $\mathrm{Ca}^{125}$ se eleva en 
estos casos, tampoco se recomienda como estudio diagnóstico de rutina $(1,2)$. El uso de imágenes como la ecografía y la tomografía es parte integral del diagnóstico, y esta última es el método más sensible para el estudio del peritoneo (6).

Con respecto a la medición de niveles de ADA con punto de corte $>30 \mathrm{UI} / \mathrm{mL}(1,3)$ y para otros, de $36 \mathrm{UI} / \mathrm{mL}(7)$, en ausencia de inmunosupresión o cirrosis, puede tener alta sensibilidad y especificidad ( $96 \%$ y $98 \%$, respectivamente) (1), de tal forma que se constituye en una herramienta muy útil, en especial en áreas endémicas con baja posibilidad de acceso a la toma de biopsia $(1,8)$.

La coloración de $\mathrm{ZN}$ es positiva en apenas el $3 \%$ de los casos y el cultivo sigue siendo la prueba de oro, para lo cual se tienen en general técnicas en medio sólido y líquido como el método de cultivo bacteriológico automatizado BACTEC, cuya ventaja es disminuir el tiempo de proceso a la mitad $(1,9)$. En una revisión sistemática, Sanai y Bzeizi reportaron positividad en el $35 \%$ de los casos (2).

En cuanto a las pruebas inmunológicas, la tuberculina no es específica para TB activa y tiene baja sensibilidad. Otras pruebas como la medición de interferón gamma (IFN- $\gamma$ ) y la inmunoglobulina $\mathrm{G}$ ( IgG) específica contra la micobacteria en ascitis son útiles, pero poco disponibles por su costo. Las pruebas moleculares como la PCR y reacción en cadena de ligasa (RCL) tienen la ventaja de ser rápidas, pero de alto costo y en ocasiones con baja sensibilidad ( 60 \%- $80 \%$ ); es mejor la última, pero está menos disponible (1). En el caso que se reporta, la PCR confirmó el diagnóstico teniendo una alta sospecha clínica y paraclínica previa.

Finalmente, la biopsia de peritoneo por laparoscopia se considera fundamental para la confirmación histológica y, ante el diagnóstico diferencial de neoplasia; actualmente también se están haciendo abordajes por vía percutánea en casos de TB peritoneal no fibroadhesiva $(1,2)$.

$\mathrm{El}$ tratamiento recomendado es el mismo que para $\mathrm{TB}$ pulmonar, siendo 6 meses la duración usual. Algunos autores sugieren prolongar el tiempo de tratamiento hasta 9 a 12 meses, especialmente en pacientes con VIH sin manejo antirretroviral $(1,5)$. El paciente que reportamos recibió manejo supervisado durante 9 meses y se observó mejoría clínica y paraclínica al finalizar la primera fase del tratamiento.

En conclusión, la TB sigue siendo una entidad con alta prevalencia, el compromiso peritoneal es el más frecuente a nivel gastrointestinal y ya que puede manifestarse con un cuadro inspecífico, se debe tener un bajo umbral de sospecha, aun en pacientes sin inmunocompromiso evidente.

\section{REFERENCIAS}

1. Guirat A, Koubaa M, Mzali R, Abid B, Ellouz S, Affes N, Ben Jemaa M, Frikha F, Ben Amar M, Beyrouti MI. Peritoneal tuberculosis. Clin Res Hepatol Gastroenterol. 2011;35(1):60-9. https://doi.org/10.1016/j.gcb.2010.07.023

2. Sanai FM, Bzeizi KI. Systematic review: tuberculous peritonitis--presenting features, diagnostic strategies and treatment. Aliment Pharmacol Ther. 2005;22(8):685-700. https://doi.org/10.1111/j.1365-2036.2005.02645.x

3. Global tuberculosis report 2019 [internet]. Génova: World Health Organization; 2019 [citado el 5 de junio de 2020]. Disponible en: https://apps.who.int/iris/bitstream/han dle/10665/329368/9789241565714-eng.pdf

4. López Pérez MP. Informe de evento tuberculosis, Colombia, 2017 [Internet]. SIVIGILA. 2018;3:1-21 [citado el 7 de junio de 2020]. Disponible en: https:// www.ins.gov.co/buscador-eventos/Informesdeevento/ Tuberculosis 2017.pdf

5. Wu DC, Averbukh LD, Wu GY. Diagnostic and Therapeutic Strategies for Peritoneal Tuberculosis: A Review. J Clin
Transl Hepatol. 2019;7(2):140-8.

https://doi.org/10.14218/JCTH.2018.00062

6. Gómez-Piña JJ. Tuberculosis peritoneal. Med Interna México. 2018;34(3):490-6.

7. Riquelme A, Calvo M, Salech F, Valderrama S, Pattillo A, Arellano M, Arrese M, Soza A, Viviani P, Letelier LM. Value of adenosine deaminase (ADA) in ascitic fluid for the diagnosis of tuberculous peritonitis: a meta-analysis. J Clin Gastroenterol. 2006;40(8):705-10. https://doi.org/10.1097/00004836-200609000-00009

8. Vaz AM, Peixe B, Ornelas R, Guerreiro H. Peritoneal tuberculosis as a cause of ascites in a patient with cirrhosis. BMJ Case Rep. 2017;2017:bcr2017220500. https://doi.org/10.1136/bcr-2017-220500

9. Arévalo C, Rosales J, Lozano D, Zurita N, Borráez Segura BA. Tuberculosis abdominal: patología infrecuente en un paciente joven. Reporte de un caso. Rev Chil Cirugía. 2017;70(4):367-72. https://doi.org/10.1016/j.rchic.2017.06.006 